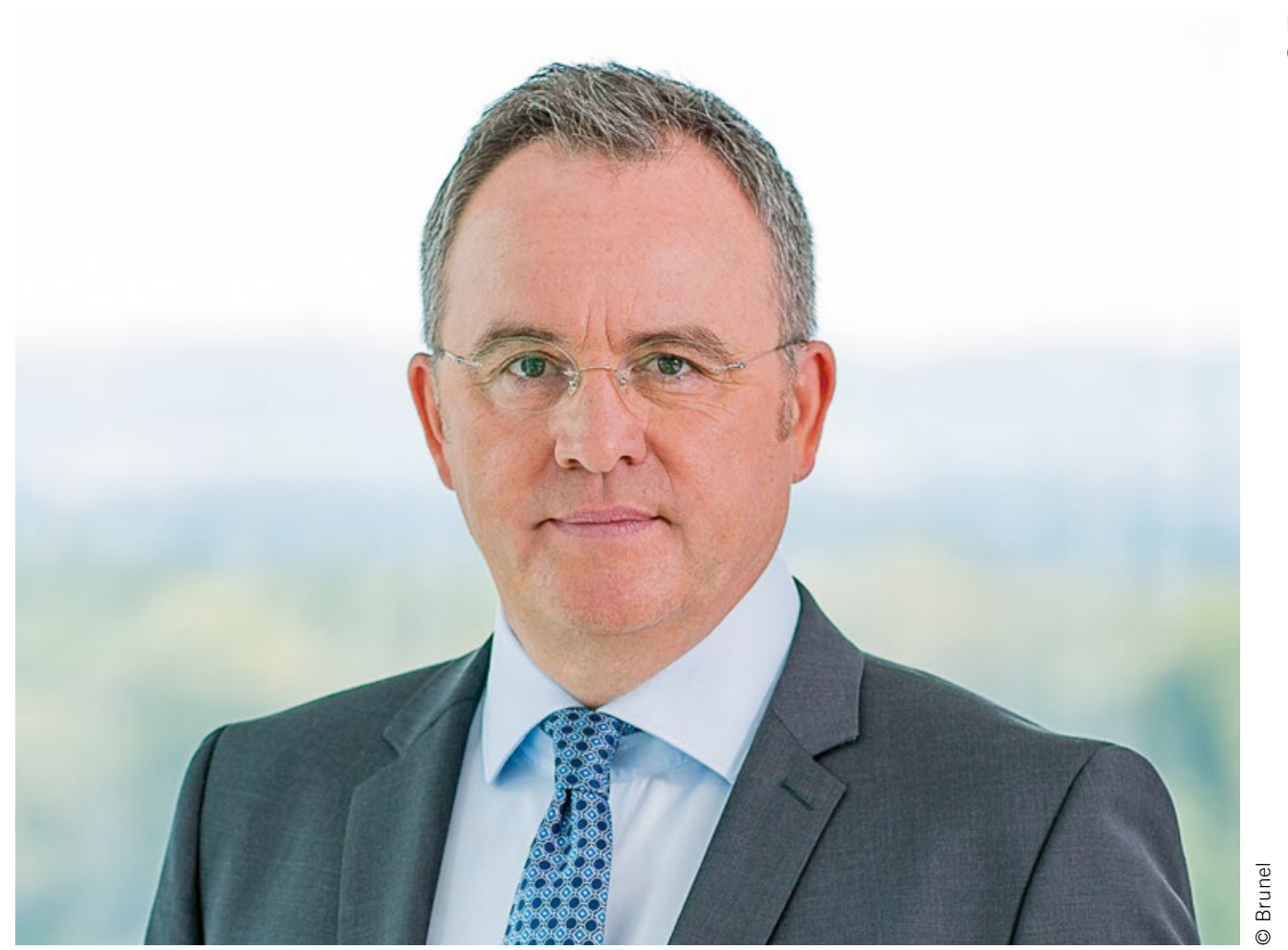

Dipl.-Ing. (FH) Markus Eckhardt Geschäftsführer der Brunel GmbH

\title{
Wichtige Investitionen in die Autoindustrie
}

Vielerorts ist von einer Krise der Automobilbranche die Rede. Aus meiner Sicht handelt es sich hierbei jedoch um eine Fehlinterpretation: Was wir sehen, ist eine Transformation eines gesamten Wirtschaftszweigs. Bedingt ist diese zum einen durch neue Wege bei den Antriebskonzepten. So erzeugen elektrisch und autonom fahrende Fahrzeuge andere Lastkollektive als ein Pkw mit Verbrennungsmotor. Sie werden über weniger Bauteile, dafür aber über mehr Software verfügen. Das Fahrzeug der mittelnahen Zukunft wird ein autonomes, vernetztes und verkehrssicheres Entertainmentsystem sein, das mit einem elektrischen Antrieb auf Basis von Batterie- oder Brennstoffzellentechnik daherkommt. Dabei wird es aus deutlich mehr Standardkomponenten bestehen als bisher.

Diese grundlegende Veränderung von Fahrzeugen stellt Hersteller und Zulieferer zum einen vor große Herausforderungen. Zumal von diesem Paradigmenwechsel neue Anbieter wie beispielsweise Apple, Google oder Sony profitieren, die nun auf den Markt drängen. Zum anderen stellen äußere Umstände die Unternehmen vor Probleme, auf die diese nur bedingt Einfluss haben: Zollstreitigkeiten, die Hängepartie rund um den Brexit oder konjunkturelle Schwankungen in starken Absatzregionen wie etwa China, die auf die Märkte drücken. Auch das Coronavirus muss an dieser Stelle erwähnt werden, auch wenn seriöse Prognosen zu dessen Auswirkungen zum jetzigen Zeitpunkt noch nicht möglich sind. Kurzum: 2020 wird ein Jahr, das die Branche noch lange in Erinnerung behalten wird.

In dieser Zeit des Wandels stellen externe Dienstleister mehr denn je eine wichtige Säule der Automobilbranche dar. Sie unterstützen die Unternehmen dabei, sich flexibel an die veränderten Rahmenbedingungen anzupassen: Ingenieurdienstleister haben beispielsweise die Aufgabe, Fachkräfte und Leistungen zur richtigen Zeit am richtigen Ort bereitzustellen. Hierzu gehen wir bei Brunel verschiedene Wege. Etwa gewährleisten wir mit unseren Talent Acquisition Centers in Frankfurt am Main, Amsterdam, Mechelen und Manchester eine frühzeitige Ansprache von Spezialisten, auch über Ländergrenzen hinweg.

Wir engagieren uns außerdem bei der Formula Student Germany oder an Hochschulen und fördern unsere Mitarbeiter individuell mit Fort- und Weiterbildungen. Ein weiterer aktueller Schritt ist der Umzug und die Investition in die Brunel Car Synergies $\mathrm{GmbH}$ von Bochum nach Dortmund in ein größeres und moderneres Betriebsgelände, wodurch wir unser Werkvertragsgeschäft für die Fahrzeugindustrie enorm ausbauen: Auf $3700 \mathrm{~m}^{2}$ werden künftig Umweltsimulationen die Validierung von Komponenten für Elektromobilität und autonomes Fahren abdecken. Mit einer verbesserten Prüflingslogistik sorgen wir gleichzeitig für eine schnellere, effizientere und präzisere Auftragsabwicklung nach modernen Lean-Methoden. 